\title{
Research on the Influence of the Grandparents' Upbringing on the Development of Children's Peer Interaction Ability
}

\author{
Sihong Zhao \\ School of Preschool Education, Xi'an University, Xi'an, Shaanxi province, 710065, China
}

41890609@qq.com

Keywords: Grandparents' upbringing; Child; Peer interaction; Influence

\begin{abstract}
This study was conducted from the perspective of grandparents. By comparing the development level and performance of the peer interaction ability of children based on grandparents' upbringing and non grandparents' upbringing, we can understand the main influencing factors and their causes of grandparents' upbringing on the development of children's peer interaction ability, so as to guide grandparents to improve their educational ideas and ways to effectively promote the development of children's ability to communicate with peers, and to achieve greater family education benefits.

The data of the questionnaire survey was analyzed by SPSS software. From the two aspects of kindergarten teachers and parents, we know the development status of children's peer interaction ability under two upbringing conditions. It is found that the influence of grandparents on children's peer interaction ability is mainly manifested in the following aspects: the educational ideas of grandparents have a direct impact on the quality of children's peer interaction; the social initiative of the grandparents plays a demonstration role in children's peer interaction ability; there is a negative correlation between the age characteristics of the grandparents and children's peer interaction ability; there is a clear positive correlation between the relationship of grandparents-grandchildren and the children's peer interaction ability.
\end{abstract}

\section{Concept Definition}

The ancestors, in the "Modern Chinese Dictionary", refer to the forefathers and forebears. In this study, the ancestor refers to the parents' older generation, that is the grandparent.

Upbringing, namely education culture, is the raising and education for children. At present, in the family education in China, two types of people are responsible for the main family education: parents and grandparents. Influenced by the traditional child-rearing pattern, grandparents will be chosen to take care of and educate the children in many families because the parents are busy with their work, which belongs to the grandparent upbringing. Some researchers divide the grandparent upbringing families into two types. One is that the children live together with their parents. However, their parents are busy with their work and usually have no time to take care of and educate them, so children's daily life and educational tasks are completed by their grandparents. The other is that the children don't live with their parents, and their parents go out to work and do not often go home. The previous case is studied in this article.

Hartup (1989) believes that the companions are those who have the same social rights as the children themselves. Interaction is the communication. One of the basic functions of interaction is to organize people to work together, to form and develop the relationship between individuals.

Therefore, the children's peer interaction ability is a comprehensive ability for children to feel, adapt, coordinate and deal with peer relationship in the process of interaction with their peers.

\section{A Comparative Study on the Children's Peer Interaction Ability under the Grandparents Upbringing and Non Grandparents Upbringing}

This study, starting from the factors of parents, studied the influence of parents on the development of children's peer interaction ability. All the children under test belonged to the large class age group. There were 200 questionnaires about peer interaction ability that should be filled out by the 
teachers and there were also 200 questionnaires that should be filled out by parents. Among them, for teachers' questionnaires, 184 questionnaires were collected, 176 questionnaires were available, the recovery rate was $92 \%$, and the effective rate was $95.7 \%$. For parents' questionnaires, 180 questionnaires were collected, 176 questionnaires were available, the recovery rate was $90 \%$, and the effective rate was $97.8 \%$. Among them, grandparents were 69 and non grandparents were 107 .

The questionnaire was set up in 5 dimensions. The score of the positive performance of children was 5,4,3,2,1 in turn, and the score of the negative expression level was 1,2,3,4,5 in turn. SPSS software was used for data processing.

The average and standard deviation of children's peer interaction ability with two kinds of parenting styles were compared. The results were shown in Table 1. The comparison results of standard deviation showed that the score of children under non grandparents' upbringing was more stable and concentrated than that of children under the grandparents' upbringing, that is, the children's peer interaction ability under non grandparents' upbringing is higher than the children under grandparents' upbringing.

Table 1 Comparison of children's peer interaction ability under two kinds of parenting styles

\begin{tabular}{lccc}
\hline MD & S & Total number \\
& & 69 & \\
Grandparents49.2 & 1.45 & & 1.37 \\
Non grandparents & 57 & & \\
107 & & & \\
\hline
\end{tabular}

An average calculation is carried out for the total score of each index, and the results are shown in Table 2, indicating that the children under grandparents' upbringing have weaker abilities in three aspects of social initiative, prosocial behavior and language and non language, and the social barriers are more obvious than those children under non grandparents' upbringing.

Table 2 Comparison of the indexes of children's peer interaction ability under two kinds of parenting styles

\begin{tabular}{lccc}
\hline $\begin{array}{l}\text { Social initiative; Prosocial behavior; Language and non language ability; Social } \\
\text { barriers }\end{array}$ & & \\
\hline $\begin{array}{l}\text { Grandparents' upbringing } \\
4.1\end{array}$ & 3.24 & 3.3 & 2.83 \\
$\begin{array}{l}\text { Non grandparents' upbringing } \\
3.4\end{array}$ & 3.52 & 3.7 & 3.3 \\
\hline
\end{tabular}

The factors of parents' interaction ability, educational requirements, the interaction quality between parents and children and the educational concepts are considered to analyze the relationship between these factors and the ability development of children's peer interaction.

We use product moment correlation to analyze data, and the correlation coefficients are all greater than 0, indicating that these factors are positively correlated with all aspects development of children's peer interaction ability. The results are shown in Table 3. For the correlation coefficient $0.4 \leq|\mathrm{r}|<0.7$, it belongs to the moderate correlation. $0.2 \leq|\mathrm{r}|<0.4$ belongs to the low correlation. The calculation formula is as follows. 


$$
\mathrm{r}_{x y}=\frac{\sum_{i=1}^{n} x_{i} y_{i}}{\sqrt{\sum_{i=1}^{n} x_{i}^{2}} \sqrt{\sum_{i=1}^{n} y_{i}^{2}}}
$$

Table 3 The correlation between parents' factors and children's peer interaction ability

Grandparents Non grandparents

Children's
peer
interaction
ability

$\mathbf{r}_{x y}$

$\mathbf{r}_{x y}$

0.40

0.57

The results show that there is a moderate correlation between grandparents upbringing and non grandparents upbringing and children's peer interaction ability.

Table 4 shows the correlation between the indicators in the parents' questionnaire and the indicators in the teacher's questionnaire. The methods of calculation are the same as above. The table shows that the parents' interaction ability is moderately related to the social initiative of the children. The requirement of parents for children is moderately related to children's social initiative and prosocial behavior. There is a moderate correlation between educational ideas and prosocial behavior, and there is a low correlation between the other indicators.

Table 4 The correlation between the indicators of parents and the indicators of children's peer interaction ability

\begin{tabular}{|c|c|c|c|c|}
\hline \multirow[t]{2}{*}{ Parents } & \multicolumn{4}{|c|}{ Requirement for children; Quality of parent-child interaction; } \\
\hline & $\mathbf{r}_{x y}$ & $\mathbf{r}_{x y}$ & $\mathbf{r}_{x y}$ & $\mathrm{r}_{x y}$ \\
\hline Social & 0.41 & 0.42 & 0.34 & 0.36 \\
\hline $\begin{array}{l}\text { initiative } \\
\text { Prosocial } \\
\text { behavior } \\
\text { Language }\end{array}$ & 0.38 & 0.40 & 0.33 & 0.42 \\
\hline $\begin{array}{c}\text { and non } \\
\text { language } \\
\text { ability }\end{array}$ & 0.33 & 0.26 & 0.31 & 0.27 \\
\hline $\begin{array}{l}\text { Social } \\
\text { barriers }\end{array}$ & 0.22 & 0.24 & 0.21 & 0.26 \\
\hline
\end{tabular}




\section{Research Results and Analysis}

The Characteristics of Children's Peer Interaction Ability under the Way of Grandparents Upbringing. The first is the weak social initiative of children. The overall level of the children's peer interaction ability under the grandparents' upbringing is lower than the children under non grandparents' upbringing(Table 1).

The second is the obvious social barriers of children. In the aspect of social barriers, children under grandparents' upbringing are generally different from those of non grandparents' upbringing(Table 2).

The third is the less prosocial behavior of children. Compared with the children under non grandparents' upbringing, children under the grandparents' upbringing have less prosocial behavior(Table 2).

The fourth is the weak development of children's language and non language ability. The differences in language and non language development of children are obvious under the two types of parenting patterns(Table 2).

The Influence Factors of the Development of Children's Peer Interaction Ability under the Way of Grandparents Upbringing. The children based on the grandparents' upbringing are lower than the children based on the non grandparents' upbringing in the aspect of the peer interaction ability. The reasons are mainly in four aspects: the idea of grandparents' upbringing, the social interaction ability of their grandparents, the harmony between grandparents and grandchildren, and the age characteristics of their grandparents.

The first is that the educational concept of the grandparents directly affects the quality of children's peer interaction. The educational concept of grandparents' upbringing can be embodied in the grandparents' requirements for children's peer interaction.

Some grandparents can recognize the important role of children's peer interaction ability to the socialization of children, so that they ask children to communicate with peers friendly. They do not order children to do something. When there are problems in the interaction between children and their peers, they will use a positive attitude to solve the problem.

However, some grandparents believe that the parents can only mange children's daily life. As for socialization, it is the problem that the preschool teachers should worry about. There are also some grandparents who are overprotective and doting on the children. In the process of children's interaction with their peers, they don't trust their children to solve their own problems, worry about children being hurt, and take their children away from their peer groups, thus children lose the opportunity to learn to solve conflicts.

Some of these factors can promote the development of children's peer interaction ability, while others may hinder the development of their interaction ability.

The second is that the social initiative of the grandparents plays a demonstration role in children's peer interaction ability.

Grandparents' own interaction ability affects their children's peer interaction ability. For the grandparents with strong social interaction ability, the children's peer interaction ability is strong.

The initial learning of children is theimitation learning. They often follow their grandparents to visit relatives and friends. Social interaction between adults is the most direct experience for young children. The children can learn a lot of social interaction skills, which can be transferred to their interaction with their peers.

Some grandparents have weak interaction ability and have no effective interaction strategies. When children's peer interaction is not going well, they can't provide effective solutions for children, so that children will not use effective interaction strategies in the interaction with their peers and the peer relationship will be affected.

The third is that there is an obvious positive correlation between the relationship between grandparents-grandchildren and the children's peer interaction ability.

The harmonious grandparents relationship is that children like and are willing to communicate with their grandparents, and the grandparents will also listen to and respond to children's complaints and talk to children about the fun of kindergarten, so that children have confidence to 
actively talk to people and have interest in communication with others.

Children will also transfer their skills of communicating with parents to peer interaction situation, which helps children form emotional transfer and form good peer relationships in the interaction with their peers.

The fourth is that there is a negative correlation between the age characteristics of grandparents and the children's peer interaction ability.

With the increase of age, the scores of the grandparents will decrease in the aspects of requirement for children's peer interaction and educational concept (Table 1). Influenced by the educational concept, the grandparents with more scientific educational concepts will also put forward more reasonable requirements and communication strategies for children's peer interaction.

Grandparents are weak in physical strength. Their physical condition is not as good as that of young children. Most of them prefer quiet, so the range of activity of children is not large. Therefore, children have fewer opportunities to contact with their peers and their peer interaction ability develops slowly accordingly — not to mention the children who are timid and introverted. They need to be constantly encouraged to interact with strangers so as to improve their confidence.

\section{Solution Strategy}

Teachers Take Corresponding Measures to Change the Concept of Grandparents' Upbringing. Teachers should take the initiative to observe and evaluate children's interaction behaviors, find out the problems existing in their peer interactions, and analyze the causes of the problems, so as to implement the solution strategies. When doing the ideological work of the grandparents, the teacher should pay attention to the individual differences and conduct the classification guidance.

The situation of the grandparents can be divided into the following. The first is the grandparents who have the right education idea but do not know how to operate, and the teachers can give them concrete and feasible plans. The second is the grandparents who have no correct upbringing concept and do not attach importance to family education, for example, they only care about the related problems in children's life. Their educational concept should be updated. Teachers can show grandparents the video of problems in the process of peer interaction and let grandparents realize the problems that exist in the process of children's development. After the teachers point out the problem, they should understand the situation of children's family education and discuss with their grandparents the educational strategies suitable for children. The third is the grandparents who attach importance to family education and have good upbringing method. It is mainly to strengthen the guidance for updating their concepts, and to hand out the related materials with a lot of modern education information, such as books, magazines, newspapers and so on. The parents corner of the kindergarten can be used well, and some scientific educational ideas can be constantly updated.

Kindergartens Carry out a Variety of Activities to Improve the Upbringing Quality of Grandparents. The kindergarten should run school for grandparents, and teach grandparents face to face. Grandparents can discuss and learn with each other. To start a grandparent school, the age characteristics of the grandparents should be considered, and the teaching content should be easy to operate, operable and correct. At the same time, the way of teaching should be diversified and the parents can share their experience together. Taking the class as the unit, the parents' meeting and the parents' open day should be held regularly. At the parents' meeting, parents can put forward their own problems, and discuss with teachers to put forward the solutions. Teachers can share the growth of children with parents to close the distance between teachers and parents.

Kindergartens can also organize many parent-child activities. Considering the physical factors of the grandparents, they can do less activities. This can not only enhance the communication between grandparents and grandchildren, but also enrich grandparents' life. Grandparents are also the resources to inherit folk culture. They are familiar with traditional folk culture, traditional folk games and so on. The kindergarten can also carry out related activities, invite the grandparents to explore old folk games, so that the peer interaction ability of children can be developed and the harmonious relationship between grandparents and grandchildren can be promoted. 


\section{Renewing the Educational Idea of the Grandparents and Improving the Their Education} Level. Children are easily affected by the values and habits of adults. For the grandparents who nurture their grandchildren, it is necessary to renew the grandparents' education ideas. The renewal of educational ideas can be done from the following aspects:

Family aspects: Professor Zhongxin Zhao has published an article saying that the most taboo in family education is that parents' requirements for children are not unified. Grandparents give a requirement to children, but their parents give another requirement to children, so it is easy for children to be confused. They have to meet different requirements. Therefore, in the education of children, parents and grandparents need to unify the concept. Grandparents and parents need to communicate more, change their incorrect educational ideas, study together, and update their educational ideas. The important thing is to communicate more and work together for the development and progress of children.

As the grandparents, they must first realize their own shortcomings, which are also the most important. They should renew their educational ideas by learning, and read the latest information of science education, such as books, newspapers, magazines and so on, and they can also learn related parenting knowledge by watching related videos and improve their education level by listening to lectures. When encountering problems, they should take the initiative to ask the teacher for advice and discuss the countermeasures together.

Improving the Grandparents' Interaction Ability and Providing the Opportunity for Children to Communicate. According to the results of the survey, there is a moderate correlation between the grandparents' interaction ability and children's peer interaction ability(Table 2), so the improvement of the grandparents' interaction ability is conducive to providing positive and effective interaction strategies and opportunities for children's social interaction. Therefore, in order to improve the children's peer interaction ability under the grandparents' upbringing, the grandparents' interaction ability should be improved first.

Grandparents should establish good relationships with their neighbors, and actively participate in public activities on weekdays. In that way, their life can be enriched and children's social space can be widened, so as to provide social interaction opportunities for children. At the weekend, they can also gather the other children in the community, so that children can play games with their peers, and they can exchange the idea of scientific education.

Improving the Interaction Quality between Grandparents and Grandchild to Create a Good Interaction Environment for Children. To improve the quality of communication between the grandparents and grandchildren, the grandparents should do the following: The first one is to actively listen to children's words, and grandparents shouldn't feel meaningless even though the child's language is simple and not logical. In the process of speaking, children's oral and language logic will be developed, and the careful listening will improve the confidence of the children to communicate with others. The second is to respond positively. A positive response to a child will give young children a sense of attention. A good and harmonious communication atmosphere also helps to enhance the desire and confidence of the children to communicate. The third is to interact with children actively. The grandparents and children can carry out the parent-child games that their grandparents can do to enhance their intimate relationship. They can also play puzzle games, tell stories, and so on. The fourth is to pay more attention to all aspects of children and invest more care and love.

Giving Full Play to the Positive Role of Grandparents' Upbringing and Promoting the Development of Children's Interaction Ability. First of all, grandparents have more experience of parenting than younger parents. When children encounter problems, they can effectively deal with children's problems. They also know more about the psychological characteristics of children in each age group than their young parents. They probably know what's going to happen, and how should they deal with it? They are also more patient and more careful than young parents in caring for children's daily life. Secondly, grandparents have more time to look after children than the children's parents. The grandparents can use their leisure time to bring children to amusement parks, to communicate with peers and to promote their peer interaction ability. Finally, grandparents are 
more experienced than the children's parent to deal with the neighbourhood relationship to provide learning and imitating situations for the development of children's interaction ability.

\section{References}

[1] H.B.Yan: Investigation and Reflection on the Status of Family Ancestral Upbringing of 3-6 Year Old Children[J], Journal of Yanbian Institute of Education, 2014(4).(In Chinese)

[2] Y.J.Li: Study on the Development of Children's Ability to Communicate with Peersand Its Influencing Factors[D], Shanghai: East China Normal University,2008.(In Chinese)

[3] H.J.Cao: The Poor Relationship between Preschool Children and Its Correction [J], Shandong Education Press, 2012(6).(In Chinese)

[4] Z.X.Zhao: Family Pedagogy, Beijing: People's Education Press, 2001.(In Chinese)

[5] X.Q.Zhou: The Development Status of Children's Social Ability in Small Classes in Urban and Rural Areas and Educational Suggestions[J], Studies in Early Childhood Education, 2010, 8, 43-46.(In Chinese)

[6] Z.X.Zhao: Educating Children should be Consistent and Unified in Attitude [J].2011.(In Chinese)

[7] Z.X.Zhao: Ways and Methods to Guide Family Education, [J].2011(7).(In Chinese)

[8] L.X.Cui: Research on the Importance and Strategy of Training Children's Social Communication Ability[J], Success Education, 2011,(8):179-180.(In Chinese)

[9] J.M.Miao: A Study on the Relationship between Children's Problem Behavior and the Way of Grandparents' Upbringing and Peer Status[D].2015.(In Chinese)

[10]J.J.Wu: The Relationship between the Parenting Style of the Grandparents and the Parents and the Adaptation of the Children's Social Emotion: The Moderating Effect of Temperament[D], Shanghai Normal University, 2016.(In Chinese)

[11]P.Kong: The Influence of Grandparents' Upbringing on Children's Peer Relationship:The Mediating Role of Children's Problem Behavior[J], Journal of Shandong Normal University, 2012.(In Chinese)

[12]Z.W.Gao: Study on the Relationship between the Relationships of Grandparents-Grandchildren and the Social Competence of Children learning in Middle Class[D], Shanghai Normal University, 2009.(In Chinese)

[13]Y.Chen: The Study of the Situation of Kindergarten Coping with Ancestral Upbringing[D], Central China Normal University, 2007.(In Chinese)

[14]J.M.Xue: A Study of the Relationship between the Way of Grandparents' Upbringing and the Social Ability of Preschool Children[D], Journal of Early Education (Scientific Research), 2013.10.(In Chinese)

[15] Y.N.Wang: Study on the Status of Family Education Guiding in Kindergartens[D], Tianjin Normal University, 2012.(In Chinese)

[16]Z.X.Zhao: Educational Concept Determines the Success or Failure of Family Education[N], People's Daily, 2013(9).(In Chinese) 